Wolf J., Anderson I., van den Dries L., Hrast M.F. (2016) The Health of Homeless Women. In: Mayock P., Bretherton J. (eds) Women's Homelessness in Europe. Palgrave Macmillan, London reproduced with permission of Palgrave Macmillan.

This extract is taken from the author's original manuscript and has not been edited. The definitive, published, version of record is available here:

https://link.springer.com/chapter/10.1057/978-1-137-54516-9 7 


\title{
The Health of Homeless Women
}

Judith Wolf, Isobel Anderson, Linda van den Dries and Maša Filipovič Hrast

\begin{abstract}
This chapter addresses the issue of the health of homeless women, which is an underresearched theme that has received little dedicated research attention in EU member states. Research evidence from across the globe indicates that maintaining good health and accessing health services is a major challenge for homeless women. However, although many researchers on homelessness include both sexes in their studies, results often do not differentiate between homeless men and women resulting in a lack of data on the health of homeless women. Research also often focuses on the most acute experiences of homelessness. This chapter presents an overview of the available international evidence on the health of homeless women and issues which influence their access to health services in different national health care systems and types of welfare.

It has revealed a somewhat patchy picture of the health of homeless women and their exclusion from health care services irrespective of differing health and welfare state systems. There is considerable evidence of relatively poor health among homeless women, including widespread experience of circulatory problems, skeletal problems (e.g. arthritis), and respiratory problems; high prevalence of cardiovascular risk factors; and experience of sexually transmitted infections (STI) and sexually transmitted diseases (STDs), mental disorders and other mental health problems. The effectiveness with which the healthcare needs of homeless women are met depends to a large degree on enabling factors such as the nature of national health services and their general accessibility, but there remains a lack of data on specific barriers that homeless women face when accessing healthcare.

The chapter concludes that there is considerable scope for further research within and across European countries to better establish how women's homelessness affects their health; how homeless women experience health care services across Europe; and to contribute, with this research, to the knowlegde base of the wider international scientific community.
\end{abstract}

\section{Introduction}

This chapter addresses the issue of the health of homeless women, which is an underresearched theme that has received little dedicated research attention in EU member states. Research evidence from across the globe indicates that maintaining good health and accessing health services is a major challenge for homeless women. Research on all aspects of the lives of homeless women in Europe is scarce (Baptista, 2010) and research on the health of women 
who experience homelessness or housing instability is even rarer. Being homeless increases health risks (Muñoz et al., 2005), decreases personal safety (Wenzel et al., 2004) and results in higher morbidity and mortality (Morrison, 2009; Nielson et al., 2011). In addition, homeless persons often do not have the financial resources to meet their health care needs, as many lack appropriate health insurance (Stein et al., 2007).

Women-specific studies indicate that gender is one of the strongest predictors of poor health among the homeless (Riley et al., 2007). However, although many researchers include both sexes in their studies, results often do not differentiate between homeless men and women (Joly et al., 2011; Jones \& Pleace, 2010), possibly due to the relatively smaller number of women counted (see Chapter 4, this volume) which prohibits statistical analyses of differences. In addition, homeless women may not be included in national health surveillance systems and data sets. This lack of data on the health of homeless women is unfortunate given (1) the relatively large absolute number of these women (see for example Jones \& Pleace, 2010) and (2) the higher prevalence of some risk factors for mental illness among homeless women compared to homeless men, such as histories of sexual child abuse and domestic violence by an intimate partner (Jonker et al., 2012; Stoltenborgh et al., 2011).

When speaking of the health (needs) of homeless women it is important to define the two main concepts of homelessness and health. For both concepts broad definitions are applied. As elsewhere in this volume, for homelessness, FEANTSA's ETHOS definition is used (Edgar and Meert, 2005), which consists of thirteen categories grouped under four headings: roofless, houseless, insecure, and inadequate accommodation. Although we wish to adopt a broad understanding of homelessness, it is important to note that in the majority of studies on homelessness and health, and consequently in the studies presented in this chapter, homelessness is more narrowly defined (see Jones and Pleace, 2010, Chapter 4, this volume) and often includes only those individuals who are residing in shelters (Caton et al., 2013; 
Wilson, 2005), sleeping rough or those who are vulnerably housed (Dealberto et al., 2011).

Moreover, in some studies it is not clear to which ETHOS category the women that are included belong.

Although it is not feasible to fully address all aspects of the health of homeless women, a wide definition of health is adopted in this chapter in order to gain insight into various dimensions of health. The definition of health used includes physical and mental health and the health consequences of substance use. Within the EU, health policy increasingly adopts such a broad definition. The World Health Organisation places universal health coverage at the forefront of achieving good health and wellbeing, taking a broad view of the services needed, from clinical care for individuals to public services that protect the health of whole populations (World Health Organization, 2013).

This chapter presents an overview of the available evidence on the health of homeless women and their access to healthcare in different national health care systems and types of welfare. We then consider some of the limitations of the evidence base in terms of understanding the health of homeless women in Europe and identify some implications for future research.

\section{Health Problems of Homeless Women}

In this section we present an overview of research on the health of homeless women from studies conducted in Europe during the period 2003-2013. As this data set was limited, we also draw on studies from further afield (mainly North America), acknowledging that studies may not be directly comparable depending on local context, policies and care systems in different countries. We do not include studies of women experiencing interpersonal violence as they are not always defined as homeless and in many EU countries there are separate service systems for these women (see Chapter 5, this volume). Homeless women are 
prone to a diverse array of, often interrelated, health problems. Here we focus on three key aspects: physical health, mental health, and problematic drug and alcohol use.

\section{Physical health}

Homeless women experience a wide variety of health problems, such as infectious and lifestyle diseases, many of which are related to their life on the streets (Muñoz et al., 2005). In Spain, the most prevalent health problems experienced by homeless women, in the past twelve months (Muñoz et al., 2005), were circulatory problems (37.1 per cent), flu or cold symptoms (33.3 per cent), skeletal problems (30.6 per cent), and respiratory problems (27.8 per cent). Among the problems that were less frequently mentioned were tuberculosis (5.6 per cent) and diabetes (2.9 per cent). In the Netherlands 86 per cent $(n=138)$ of homeless female young adults using shelters for homeless youths reported physical health problems in the past 30 days including headaches and stomach problems (Altena et al., 2009).

Many studies on the physical health of homeless women, especially in the US, assess the prevalence of sexually transmitted infections (STI's), including HIV and sexually transmitted diseases (STD's) because of concerns about high rates of HIV among homeless populations which are partly related to the high-risk sexual and drug-using behaviour in this population (Robertson et al., 2004). The reported prevalence of STI's and STD's varies greatly between various studies, probably due to diverging target populations, recruitment sites, and sampling strategies (Robertson et al., 2004). For example, in a sample of women recruited from Russian homelessness centres, 75 per cent of the women were diagnosed with an STI (Shakarishvili et al., 2005) and 2.4 per cent were HIV positive. In a Spanish study however only 5.6 per cent of 36 sheltered and rough-sleeping women had an STD and 11.4 per cent had received a diagnosis for hepatitis or jaundice. In this sample almost a quarter of the women (22.2 per cent) had HIV/AIDS. In a comparison group of poor, housed, women who used homelessness services such as soup kitchens, the percentages of women with an 
STD and a diagnose of hepatitis or jaundice was similar. However, the percentages of women with HIV/AIDS in the sample of housed women was considerably lower (3.2\%) (Muñoz et al., 2005). In a sample of 329 homeless women, recruited from 28 family or single adult shelters in New York city, chlamydia and gonorrhoea were found in, respectively, 6.7 per cent and 0.9 per cent of the women; 0.6 per cent of the women had HIV (Caton et al., 2013). In a subsample of 190 single homeless women also in New York city, 36 per cent had HIV or an STI (Houston et al., 2013), while in a sample of sheltered women in the Midwest, who were homeless due to relationship conflicts, 16.8 per cent of the women had an STD (Wilson, 2005).

Despite the limited comparability of studies due to diversity in settings, populations, and research methods, research evidence points to the poor physical health of homeless women, emphasizing circulatory problems; skeletal problems (e.g. arthritis); respiratory problems (chronic bronchitis, asthma); cardiovascular risk factors (diabetes, hypertension, or obesity); and experience of sexually transmitted infections/diseases (STIs/STDs).

\section{Mental health}

Several studies show disproportionately high rates of psychiatric disorders and mental health problems in homeless women (Robertson and Winkleby, 1996; Nielson et al., 2011). However, since studies often measure related but not identical aspects of women's mental health ${ }^{1}$ in divergent samples using various measuring instruments, drawing clear-cut conclusions about the prevalence of mental health problems among homeless women (or comparing homeless women with other groups or the general population) is difficult. In this section findings are reported from a selection of studies on general mental health and on

\footnotetext{
${ }^{1}$ Constructs used to measure general mental health vary from the prevalence of lifetime mental health problems (Edens, Mares and Rosenheck, 2011), to the occurrence of mental illness (Zugazaga, 2004) or the presence of mental disorders (Strehlau, Torchalla, Li, Schuetz and Kraus, 2012).
} 
specific aspects of mental health, namely post-traumatic stress disorder (PTSD), depression, schizophrenia and suicidal ideation.

In Denmark, a large cohort study of homeless people, aged 16 years and older, reported registered psychiatric disorders in 58.2 per cent of the 9,671 homeless women included in the Danish Homelessness Register (Nielson et al., 2011). In this study no general population comparison figure was provided. In the UK, 77.8 per cent of 72 statutorily homeless women living in council-run temporary accommodation for homeless families scored within the clinical range on the General Health Questionnaire, indicating the likelihood of mental health problems (Tischler and Vostanis, 2007).

In line with the high rates of histories of abuse, ongoing traumatic events and revictimization typically evidenced in samples of homeless women throughout Europe and in the US, rates of PTSD have been found to be high in both adult and youth homeless populations, particularly among women (Stewart et al., 2004; Taylor \& Sharpe, 2008). However, the prevalence of PTSD varies enormously between the various studies. In the US, lifetime rates of PTSD varied from around 8 per cent among adult chronically homeless women (Edens et al., 2011) to a percentage of 51.8 for histories of PTSD among 83 unaccompanied young homeless women (Crawford et al., 2011).

Other studies have found high rates of depressive symptoms among homeless women (as high as 62 per cent in Tucker et al. 's (2005) sample of US women with a history of homelessness). Similarly, more than half (58 per cent: $n=138$ ) of the homeless female young adults using Dutch shelters for homeless youths reported depressive symptoms, as measured using the Centre for Epidemiological Studies Depression Scale (CES-D) (Altena et al., 2009) Rates of schizophrenia in populations of homeless women are high. In a Swedish study of homeless patients admitted to hospital care for mental disorders, 15 per cent of the 340 women had schizophrenia as a primary or secondary diagnosis (Beijer and Andreasson, 
2010). Women in this study were almost three times as likely to have schizophrenia compared with their homeless male counterparts and their risk of schizophrenia was 38 times higher than in control group of women from the general population. A large study based on the Danish Homelessness Register, reported a slightly lower rate of diagnosed schizophrenia, with 11.6 per cent of 9,671 women having a diagnosis of a schizophrenia spectrum disorder (Nielson et al., 2011). Furthermore, rates of schizophrenia amongst homeless women at 16 per cent and 18 per cent respectively, were reported in recent Canadian and American studies (Dealberto et al., 2011; Edens et al., 2011).

Suicidal thoughts and ideation are common among homeless women. Using the General Health Questionnaire - 28 Muñoz et al. (2005) reported suicidal thoughts in 42.6 per cent of 36 homeless women studied in Spain, but 12.9 per cent for a control group of 31 women at risk of homelessness (using services for the homeless, such as a soup kitchen, but still housed). In the Netherlands and also in Canada, actual suicidal attempts were studied amongst homeless women. In homeless female young adults in the Netherlands $(\mathrm{N}=138) 37$ per cent had attempted suicide (Altena et al., 2009). In Canada, in a population of homeless women living in shelters or on the streets, this percentage was higher (50 per cent) (Torchalla et al., 2011).

Again, there are constraints and limitations that do not permit firm conclusions to be drawn. Studies have used different methodological approaches and included different target groups. A standard definition of mental health is lacking and different measures have been used to assess the prevalence of mental health disorders. Nonetheless, the available data demonstrate disproportionately high rates of mental health problems among homeless women, including high rates of depressive symptoms, depressive disorders, PTSD and schizophrenia as well as high occurrence of suicidal thoughts and suicidal attempts.

\section{Substance use}


It is widely acknowledged, that the prevalence rate of substance use in the homeless population is higher than in the housed population (Kemp et al., 2006; McVicar et al., 2015) and that substance use can be a predictor of or reason for becoming homeless (Mayock and Sheridan, 2012; McVicar et al., 2015). In addition to being one possible cause of homelessness, (increased) substance use can also be a result of living on the streets or in homelessness hostels (Mayock et al., 2015). Research that specifically focuses on homeless women found relatively high levels of alcohol and drug use, although notable variations by subgroups of homeless women exist (Wright and Tompkins, 2006). Compared to housed women, Wenzel et al. (2004) found that women living in homelessness shelters ${ }^{2}$ were three times more likely to have used drugs in the past 12 months and 13 times more likely to have been alcohol or drug dependent.

In a number of European studies homeless women frequently initiated drug and alcohol use early (often during their teenage years) but their consumption typically increased after they became homeless or when housing situations were threatened (Anderson et al., 1993; Mayock and Sheridan, 2012). In addition, alcohol/drug use frequently emerge as playing a direct or indirect role in women becoming homeless (Mayock and Sheridan, 2012; O'Carroll and O'Reilly, 2008). The results of a large Danish study demonstrate high levels of reported substance use among homeless women. In this study, 36.9 per cent $(\mathrm{N}=3,564)$ of the almost 10,000 homeless women included in the Danish Homelessness Register had a substance abuse diagnosis (Nielson et al., 2011).

Some small-scale EU studies also show high substance use rates. In Spain, Muñoz et al. (2005) studied homeless women's drug use in the past 6 months, and reported use rates for sedatives (22.9 per cent), heroin (17.1 per cent), cocaine (14.3 per cent), cannabis (5.7 per

\footnotetext{
${ }^{2}$ In this US study women were defined as 'sheltered' when they "were sampled from facilities with a simple majority of homeless residents (persons who would otherwise live in the streets or who sleep in shelters and have no place of their own to go)." (p. 618)
} 
cent), and other substances (8.3 per cent). In Ireland, Smith et al. (2001) reported that while drug abuse had been a feature of life for many homeless young women with children in Dublin, the majority were availing of drug treatment services. Forty-seven percent of the women had used heroin, 44 per cent had used cannabis, and ecstasy had been used by 36 per cent. In another Irish study (Mayock \& Sheridan, 2012), 60 per cent of homeless women reported a current or past substance abuse problem and in a Dutch sample of female homeless young adults 26 per cent used drugs (mainly cannabis) on an almost daily basis (Altena et al., 2009).

\section{The added impact of homelessness}

Many of the physical, mental and substance related health problems experienced by homeless women are not unique to homelessness. A higher prevalence of health problems, compared to, for example, women with a high socioeconomic status, is also present in housed women living in poverty (Muñoz et al., 2005) and among housed women who (ab)use substances (Center for Substance Abuse Treatment, 2009). These similarities may be related to shared risk factors, such as poverty and substance use. This raises the question of how far the poor health of homeless women is due to their homelessness, and how far it is associated with other risk factors, which may also have played a role in their homelessness. The literature provides several explanations as to why homelessness itself can be an important risk factor for poor health.

First, becoming homeless means losing one's home, neighbours, social roles and, perhaps even, friends and family. These traumatic losses can cause psychological trauma (Goodman et al., 1991). For some women, becoming homeless happens alongside being separated from their children (see Chapter 7, this volume). This separation can overwhelm women with feelings of loss (Barrow \& Laborde, 2008 cited in Paquette \& Bassuk, 2009) and distress (Mayock, et al., 2015). Second, poor living conditions on the street may make 
homeless people more vulnerable to physical health problems and may exacerbate the already poor mental health of some women (Goodman et al., 1991; Muñoz et al., 2005). Living on the streets means women have to endure the physical hardships, such as harsh weather conditions, threatened/actual physical or sexual abuse, and a lack of sufficient food and the absence of basic facilities for personal care. In addition, they may experience feelings of loneliness, a lack of social support, and a loss of safety, predictability and control (Goodman et al., 1991; Muñoz et al., 2005). Women who live in homelessness shelters also experience life as extremely unpleasant, describing hostel life as chaotic and stressful, where women lack privacy, feel infantilized by the staff and have difficulty in dealing with the daily routine (Mayock et al., 2015). The high prevalence of stressful life events experienced by homeless women (for example, assault, victimisation and rape) also impact health (Muñoz et al., 2005). Analysis of the added impact of homelessness on health necessitates comparing homeless people with those who share some key characteristics, but are housed. Muñoz et al. (2005) compared the health status of homeless women in Spain to poor, housed, women who used homelessness services such as soup kitchens, demonstrating the impact of homelessness on several, but not all, aspects of women's health. In both groups, similar percentages of women had tuberculosis, respiratory problems, skeletal problems, hepatic problems, sexually transmitted diseases, hepatitis, jaundice and symptoms of anxiety. However, important differences were also present. Six to seven times more homeless women reported AIDS/HIV and skin disorders, compared to the at-risk women who were housed; and circulatory problems were present in almost three times as many women in the homeless population. The homeless women reported a significantly higher number of health problems and more homeless women reported depressive symptoms and suicidal thoughts. In the previous six months, the homeless women had used heroin five times more frequently, compared to the at- 
risk women, while percentages of women using cocaine, cannabis, sedatives and other substances were comparable.

Other studies confirm the added effect of homelessness. For example, Rayburn et al. (2005) studied the influence of traumatic events on the mental health of both sheltered homeless and low-income housed women finding that living in a homelessness shelter was associated with a twofold increase in the risk of depression which the researchers attributed to the condition of homelessness itself. Although several studies suggest an added effect for homelessness, it is almost impossible to be certain that homelessness itself either causes or exacerbates the health problems of homeless women. For example, the poor mental and physical health of homeless people may, at least in part, be a delayed consequence from the disadvantageous conditions they experienced before becoming homeless. Similarly, previous periods of homelessness may have a lifelong negative effect on the health of housed people but their poor health cannot always be directly linked to previous homelessness.

Finally, homelessness itself appears to be an important obstacle in accessing and receiving appropriate treatment and healthcare, as discussed in the next section.

\section{Access to Health Services for Homeless Women}

The effectiveness with which the health care needs of homeless women are met will be a function of the nature of national health services (often determined by wider welfare regimes); the success with which homeless women can access these services; and the efficacy of those services in meeting the specific health care needs of homeless women. The degree of integration of health, housing and homelessness services at strategic and implementation levels will also influence the effectiveness of outcomes. This section considers the significance of national health and welfare systems for the health of homeless women and 
assesses the evidence available on the barriers they may face in accessing services to meet their health care needs.

Since World War II, health care systems have been a core pillar of welfare provision in many European countries with resultant typologies of 'the health care state' identified as useful for analysing health policy (Burau and Blank, 2006). International bodies such as the OECD have characterised national systems according to the mix of private and public finance and service provision (Anderson et al., 2006). National systems for health care are likely to reflect wider welfare regimes (for a more detailed account of welfare regimes and homelessness see Chapter Three, this volume) but, as with housing systems, may not align perfectly with the standard typology of universal, corporate, liberal, southern European, and post-socialist structures. For example, Anderson et al. (2006) reported the range of systems shown in Figure 6.1 below.

Figure 6.1: Health care systems in selected European countries

\begin{tabular}{|l|l|l|l|}
\hline Country & Welfare Regime & $\begin{array}{l}\text { Health Care } \\
\text { System }\end{array}$ & Health care for homeless people \\
\hline $\begin{array}{l}\text { United } \\
\text { Kingdom }\end{array}$ & Liberal & Universal & $\begin{array}{l}\text { Universal entitlement to mainstream } \\
\text { services but barriers to access result in } \\
\text { some specialist service provision }\end{array}$ \\
\hline Denmark & Universal & Universal & Mainstream services \\
\hline Portugal & Southern European & Universal & $\begin{array}{l}\text { Acknowledgment of difficulty in } \\
\text { guaranteeing access to health care for } \\
\text { excluded groups }\end{array}$ \\
\hline Netherlands & Corporate/universal & Insurance based & $\begin{array}{l}\text { Homeless people are officially entitled } \\
\text { to general health care services, but in } \\
\text { practice also use local services (aimed } \\
\text { at vulnerable groups) which } \\
\text { maintain/enhance the safety net. }\end{array}$ \\
\hline Greece & Southern European & $\begin{array}{l}\text { Public and private } \\
\text { mix }\end{array}$ & $\begin{array}{l}\text { Homeless people are entitled to public } \\
\text { services, supplemented by NGO } \\
\text { services specifically for homeless } \\
\text { people. }\end{array}$ \\
\hline Austria & Corporate & Insurance based & $\begin{array}{l}\text { Health services are accessible to all, } \\
\text { with or without insurance, apart from } \\
\text { retention for administration and hotel } \\
\text { costs of hospital care. }\end{array}$ \\
\hline Slovenia & Post socialist & $\begin{array}{l}\text { Insurance based } \\
\text { (Compulsory and } \\
\text { voluntary } \\
\text { insurance) }\end{array}$ & $\begin{array}{l}\text { The majority of homeless people, if } \\
\text { they have permanent residence and } \\
\text { receive cash benefits are entitled to use } \\
\text { the regular health system. }\end{array}$ \\
\hline
\end{tabular}


In the above systems, homeless women (and men) largely have the same entitlement to health care services as the majority population in settled housing. However, the extent to which they can effectively access these services may vary across health and welfare systems. Where homeless people face barriers to general health services, alternative 'specialist' services such as the delivery of health care in day centres or temporary accommodation may emerge. As might be expected, access to general health services appears to be most universal in the Nordic states. For example, in Norway, any specialist health care services tend to be provided on the basis of health care need (such as for substance use) rather than because of any homelessness status (Anderson and Ytrehus, 2012). Similarly, in Slovenia research indicated that the majority of homeless persons found health care services accessible (Razpotnik \& Dekleva 2009a, b). In Ireland's liberal regime, homeless people's exclusion from health care has been recognised even in a period of national economic boom (O'Carroll and O'Reilly, 2008).

Although there is evidence from a number of countries that homeless people may well experience exclusion from health services to which they are entitled, there is a lack of evidence in relation to gender, other than the extent to which men and women, or different household types, may be treated equally or differently within national health and welfare systems. For example, services developed to serve a historic 'male breadwinner' family model may disadvantage non-nuclear households and employment-based insurance systems may disadvantage women if they face structural disadvantage in the labour market. In the UK, Anderson et al. (1993) reported that, among single homeless people in England, there was little difference between men and women in the extent to which they were registered with a General Practitioner (GP) or knew of a medical centre they could go to if they were unwell. In Jones' (1999) study of homeless women in England, many women who slept rough or stayed 
with friends close to their former home were registered with their own GP, while others who moved around more were not registered with a GP. Few women reported problems accessing health services, and although many did not seek services if they did not feel ill or in need of treatment, one participant described the substantial difficulties she encountered:

It was being homeless that made me drink and led to my health problems. I've also got a really bad chest and chilblains. The only doctor available was at ... a drop in service... and it was disgusting infested, blood and needles on the floor. Someday centres had all sorts coming in - alternative therapists. There's not much health care for the homeless. I had to go to hospital when I was ill ...they can be funny like 'why don't you go to see your own GP?' 'Because I don't have one' Why don't you have one?' 'Because I haven't got a home'.... they left me waiting for ages. I still didn't have a GP, I was treated in Outpatients (from 'Trish, aged 27, London', in Jones, 1999, pp.60-63).

There may be a number of reasons why homeless people may not effectively access general health services. Cultural barriers to accessing health services may include feelings that staff stigmatise homeless people as well as differing expectations of health and care services or negative experiences in the past. More personal or individualised barriers could include low self-esteem associated with homelessness; and lack of organisational skills or capacity associated with cognitive impairments, substance use or other health conditions which impact on ability to keep appointments.

Research from the UK indicates that key factors acting as barriers to accessing GP services include administrative systems such as how health services operate according to catchment areas; use of a fixed address for registration systems; reluctance to engage with patients assumed to be drug users; and low self-esteem and stigmatisation among homeless 
people (Pleace et al., 2000). As noted, one of the consequences of homeless people's exclusion from mainstream health services has been the development of alternative provision. Specialist services are often delivered through accommodation or specialist clinics for homeless people. In an international review, Pleace and Quilgars (2004) identified adaptations to exiting services, specialist primary care services, and specialist complementary services (for example, alcohol and drug support, dentistry, podiatry, and opticians): but found limited evaluative evidence of their effectiveness. There has been considerable debate around the necessity of specialist services compared to the need to better ensure homeless people's inclusion in mainstream services (Anderson et al., 2006; FEANTSA 2006, 2011; Joly et al., 2011; Jones and Pleace, 2010; O'Carroll and O'Reilly, 2008), with Anderson and Ytrehus (2012) concluding that specialist health care provision for homeless people should be transitional and ultimately designed to aid reintegration into mainstream services.

There has been little explicit consideration of homeless women's access to health care services but they may well have particular needs (for example, linked to contraception, pregnancy and motherhood, and to domestic violence) that might need to be addressed differently than the health needs of homeless men (Gelberg et al., 2004; Mayock and Sheridan, 2012). Consequently, the types of interventions needed and accepted might differ from the male homeless population. In Smith et al. 's (2001) study of the health service use of homeless women and their children in Dublin, use of health services appeared high, but many of the problems reported by women remained untreated and there was confusion about free service entitlement and access. High levels of physical and sexual abuse experienced by women meant that providing adequate strategies for intervention and care was particularly challenging, and the health and educational needs of children were compromised by the living conditions of their homeless mothers. 
The need for more effective interagency work across housing, homelessness and health services is increasingly recognized as a requirement for improving homeless people's access to health care services (Anderson and Ytrehus, 2012; Cornes et al., 2011; Joly et al., 2011). Although there is a lack of evidence on the specific experiences of women, research from Ireland illustrated how health interventions such as discharge from (and repeated admission to) psychiatric hospitals can contribute to women's homelessness (Mayock et al., 2015). Policies and practice interventions which have developed in response to acknowledgment of the health care needs of homeless people and the barriers they face in accessing health care services, can be illustrated in examples from two insurance based health care systems (the Netherlands and Slovenia) and one universal system (the UK).

In the Netherlands, homeless people who have basic health insurance can access basic medical care, but health care outside the basic package may be out of reach. Dutch Municipal Health Services (MHSs) have developed a wide range of care for socially vulnerable groups including needle exchange surgeries for homeless women working as sex workers. The Strategy Plan for Social Relief (Netherlands Ministry of Health, 2006) provided roofless people with treatment and rehabilitation packages as part of addiction policies and psychiatric services and the plan was implemented by local authorities responsible for homelessness including women's homelessness shelter services. Similar to the Netherlands, in Slovenia homeless people also have access to basic medical care based on health insurance and a majority of homeless people reported health services as accessible when needed (Razpotnik \& Dekleva 2009). Barriers identified by some of those in the Slovenian study included: not providing for the specific needs of the homeless (e.g. post-acute care, treatment of those with substance use problems); prejudices of medical personnel; limited working schedule of general practitioners; poor skills for working with those with complex needs; and not having health insurance. Emergency healthcare services have developed in larger cities, including, 
for example, gynaecology and paediatric care which address the health needs of women and mothers. However homeless people became a minority of emergency service users as a visible effect of the economic crisis in Slovenia was the increasing number of non-homeless people who had difficulties accessing regular health care (STA, 2012).

Health policy is a devolved matter in the UK, and the Scottish Parliament developed a strategic approach to addressing the health care of homeless people after the Homelessness Task Force (2002) recognised their exclusion from mainstream health services. The health needs of homeless people were recognised as part of the national goal of reducing health inequalities (Health Scotland, 2004) and in 2005 Health and Homelessness Standards were introduced (Scottish Executive, 2005) although there was no performance requirement relating specifically to homeless women. By 2015 homelessness prevention was increasingly recognised as a public health issue and a research review resulted in a renewed focus on the health service contribution to reducing the health inequality faced by homeless people (Hamlet and Hetherington, 2015). Although this broad review did not make specific recommendations in relation to homeless women, the continuing equalities approach to addressing the health issues faced by homeless people implies scope to develop gender specific responses to meeting health care needs.

Available evidence on access to health care for homeless women suggests that while it is widely acknowledged that under all health and welfare systems some homeless people face considerable barriers to accessing care, there remains a lack of detailed evidence on the differing experiences of men and women. Similarly, while policy and practice initiatives to enhance health care and successful rehousing for homeless people can be identified, there is a 
lack of robust data on the extent to which they have a positive impact on the health of homeless and formerly homeless women.

\section{The health of homeless women in Europe: assessing the research evidence}

This chapter has presented an overview of international research on the health problems of homeless women and issues which influence their access to health services. In this section we assess findings and limitations of the evidence base in relation to the experiences of homeless women in Europe.

There is undoubtedly considerable evidence of relatively poor health among homeless women in the international literature. While the prevalence of specific health issues varies between subgroups of homeless women (Teruya et al., 2010), overall the studies reviewed point to a bleak picture of homeless women's health, including widespread experience of circulatory problems, skeletal problems (e.g. arthritis), and respiratory problems; high prevalence of cardiovascular risk factors; and experience of sexually transmitted infections (STI) and sexually transmitted diseases (STDs). Studies also demonstrate disproportionately high rates of both major mental disorders and other mental health problems in homeless women. Some studies have linked substance use to coping strategies and also to other issues such as sex work. The most common substances used among homeless women seem to be alcohol and cannabis. The prevalence rates for alcohol use and especially drug dependence are higher in samples of street homeless women with higher rates of crack cocaine and heroin use also found in street homeless populations. Research study participants included a diversity of women with respect to age, marital status, race and ethnicity, duration of homelessness and role (being a mother, a sex worker and so on), but those who were young, single, roofless, long-term homeless, or were sex workers were amongst the most vulnerable within the populations of homeless women (Arangua et al., 2005; Hwang et al., 2013). 
Despite an extensive international research literature on homelessness and health, knowledge about the health problems of homeless women in Europe is limited for a number of reasons. Relatively few studies have specifically examined the health of homeless women, while other studies often do not differentiate between homeless men and women. Research on health characteristics may be undertaken quite separately from research into other dimensions of homelessness and housing; and definitions of health and homelessness vary between studies. There is also considerable variation in the methodological approaches used, particularly in relation to different measures to assess physical and mental health status of homeless research participants. There is a lack of research which addresses issues of cause and effect in relation to the specific impact of homelessness on health (as opposed to a general association between homelessness and certain health conditions), although the study by Muñoz et al. (2005) in Spain indicated some added impact of homelessness on women's health.

Within Europe, research on the health of homeless women is mostly concentrated in the UK and other north/west European countries. With the notable exception of the Muñoz et al. (2005) Spanish study, there is less evidence available from south, central and eastern European countries. The international evidence base is heavily influenced by studies conducted in North America and the extent to which their findings are applicable to the European context is difficult to gauge. The studies reviewed for this chapter were mainly national studies or smaller scale local studies and there seems to be a significant lack of international comparative research on the health of homeless women.

In the European context, the ETHOS typology of homelessness situations has been widely adopted to facilitate international comparison, but sampling strategies in studies of the health characteristics of homeless women do not necessarily fit or address the ETHOS categories. Most studies have included samples of women sleeping rough or women residing 
in different types of shelters, thus focusing on the two ETHOS-categories of homelessness which represent the most visible forms of homelessness (rooflessness and houselessness). The two broader ETHOS categories, that is, those living in insecure and inadequate housing (living temporarily with friends, in unfit dwellings, under threat of eviction, etc.) are rarely included and so comparative insight into the impact of these housing circumstances (including different forms of housing exclusion and or poverty) on the health of women seems to be lacking.

This chapter attempted to apply a wider understanding of health, encompassing physical and mental health, substance use and also general wellbeing. However, the research evidence base tended to focus on issues of physical and mental health and substance use, rather than the general well-being of women, which remains a topic that needs greater attention and discussion.

The use of healthcare by the homeless population has been linked to predisposing factors (such as demography, psychological distress), enabling factors (for example, insurance, sources of care) and need (Stein et al., 2007). Although limited, existing research indicates that differences among homeless women (for example single women or mothers and racial differences) should be taken into account when developing preventive or treatment approaches (Teruya et al., 2010; Zugazaga 2004).

The effectiveness with which the healthcare needs of homeless women are met depends to a large degree on enabling factors such as the nature of national health services and their general accessibility. There remains a lack of data on specific barriers that homeless women face when accessing healthcare and on the effectiveness of approaches for improving homeless women's access to health care.

\section{Conclusion}


This chapter has revealed a somewhat patchy picture of the health of homeless women in Europe and their exclusion from health care services irrespective of differing health and welfare state systems. There is considerable scope for further research within and across European countries to better establish how women's homelessness affects their health and how homeless women experience health care services across Europe. New research within Europe could usefully incorporate the broader ETHOS categories of women living in insecure and inadequate housing (as well as those of street homelessness and hostel accommodation) to ascertain whether significant differences in health issues emerge when applying a broader definition of homelessness. Future research could also adopt a broader conception of health as wellbeing, as opposed to focusing on specific medical conditions. Research methods could usefully embrace comparative approaches, both internationally and in relation to different housing and homelessness circumstances. The development of more robust evaluative methods would enable research to better inform the planning and delivery of integrated interventions to address the health and wellbeing of homeless women. Overall there remains scope for a much more substantive European evidence base on the health of women experiencing homelessness and housing exclusion within the context of evolving housing and health care systems across the European Union. 


\title{
References
}

\author{
Altena, A., Jonker, I, \& Wolf, J. R. L. M. (2009). Onderzoek naar meiden en moeders \\ in de residentiële opvang. Houvast: De ontwikkeling van een passende interventie voor \\ dakloze jongeren. Study on girls and mothers in residential care. Houvast: The development \\ of an appropriate intervention for homeless youth. Nijmegen: UMC Radboud. Nijmegen: \\ Impuls - Netherlands Center for Social Care Research, Department of Primary and \\ Community Care, Radboud university medical center'
}

Anderson, I., Baptista, I., Wolf, J. R. L. M., Edgar, B., Sapounakis, A., \& Schoibl, H. (2006) The Changing Role of Service provision: Barriers of access to Health Services for homeless people. Brussels: FEANTSA.

Anderson, I., Kemp, P., \& Quilgars, D. (1993). Single homeless people. London: HMSO

Anderson, I. \& Ytrehus, S. (2012) Reconceptualising approaches to meeting the health needs of homeless people. Journal of Social Policy, 41: 551-568.

Arangua, L., Andersen, R., \& Gelberg, L. (2005). The health circumstances of homeless women in the United States. International Journal of Mental Health, 34 (2): 62-92.

Baptista, I. (2010). Women and Homelessness in Europe. In E. O’Sullivan, V. BuschGeertsema, D. Quilgars , \& N. Pleace (Eds.), Homelessness Research in Europe: Festschrift for Bill Edgar and Joe Doherty. Brussels: FEANTSA, pp.163-186.

Beijer, U., \& Andreasson, S. (2010). Gender, hospitalization and mental disorders among homeless people compared with the general population in Stockholm. European Journal of Public Health, 20: 511-516. 
Burau, V., \& Blank, R. (2006). Comparing health policy: An assessment of typologies of health systems. Journal of Comparative Policy Analysis, 8: 63-76.

Caton, C. L. M., El-Bassel, N., Gelman, A., Barrow, A., Herman, D., Hsu. E. \& Felis, A. (2013). Rates and correlates of HIV and STI infection among homeless women. AIDS and Behaviour, 17: 856-864.

Center for Substance Abuse Treatment. Substance Abuse Treatment: Addressing the Specific Needs of Women. Treatment Improvement Protocol (TIP) Series 51. HHS Publication No. (SMA) 09-4426. Rockville, MD: Substance Abuse and Mental Health Services Administration.

Cornes, M., Joly, L., Manthorpe, J., O’Halloran, S., \& Smyth, R. (2011). Working together to address multiple exclusion homelessness. Social Policy and Society, 10: 513-522.

Crawford, D. M., Trotter, E. C., Hartshorn, K. J. S., \& Whitbeck, L. B. (2011). Pregnancy and mental health of young homeless women. American Journal of Orthopsychiatry, 81: 173183.

Dealberto, M. C. C., Middlebro, A., \& Farrell, S. (2011). Symptoms of schizophrenia and psychosis according to foreign birth in a Canadian sample of homeless persons. Psychiatric Services, 62: 1187-1193.

Edens, E. L., Mares, A. S., \& Rosenheck, R. A. (2011). Chronically homeless women report high rates of substance use problems equivalent to chronically homeless men. Women's Health Issues, 21: 383-389.

Edgar, W., \& Meert, H., (2005) Fourth Review of Statistics on Homelessness in Europe. The ETHOS Definition of Homelessness. Brussels: FEANTSA.

FEANTSA (2006). The right to health is a human right: ensuring access for people who are homeless. Brussels: FEANTSA. 
FEANTSA (2011). Homeless health, health and homelessness: overcoming the complexities. Homeless in Europe, Spring Issue. Brussels: FEANTSA.

Gelberg, L., Browner, C., Lejano, E., \& Arangua, L. (2004). Access to women's health care: A qualitative study of barriers perceived by homeless women. Women \& Health, 40: 87-100.

Goodman, L., Saxe, L., \& Harvey, M. (1991). Homelessness as psychological trauma. American Psychologist, 46: 1219-1225.

Gwadz, M. V., Nish, D., Leonard, N. R., \& Strauss, S. M. (2007). Gender differences in traumatic events and rates of post-traumatic stress disorder among homeless youth. Journal of Adolescence, 30: 117-129.

Hamlet, N. and Hetherington, K. (2015) Restoring the Public Health response to homelessness in Scotland. Edinburgh: Scottish Public Health Network.

Health Scotland (2004). Delivering health care to homeless people: An effectiveness review (Research in Brief, 13). Edinburgh: NHS Health Scotland.

Homelessness Task Force (2002). An action plan for prevention and effective response. Homelessness Task Force Final report. Edinburgh: Scottish Executive.

Houston, E., Sandfort, T. G. M., Watson, K. T., \& Caton, C. L. M. (2013). Psychological pathways from childhood sexual and physical abuse to HIV/sexually transmitted infection outcomes among homeless women: The role of posttraumatic stress disorder and borderline personality disorder symptoms. Journal of Health Psychology, 18 (10): 1330-1340.

Hwang, S. W., Chambers, C., Chiu, S., Katic, M., Kiss, A., Redelmeier, D. A., \& Levinson, W. (2013). A comprehensive assessment of health care utilization among homeless adults under a system of universal health insurance. American Journal of Public Health, 103: S2.

Joly, L., Goodman, C., Froggatt, K., \& Drennan, V. (2011). Interagency working to support the health of people who are homeless. Social Policy and Society, 10: 523-536. 
Jones, A. (1999) Out of sight out of mind. London: Crisis.

Jones, A., \& Pleace, N. (2010). A review of single homelessness in the UK 2000-2010. London: Crisis.

Jonker, I.E., Sijbrandij, M., \& Wolf, J. R. L. M. (2012). Toward needs profiles of shelterbased abused women: A latent class approach. Psychology of Women Quarterly, 36: 38-53.

Kemp, P., Neale, J. and Robertson, M. (2006) Homelessness among problem drug users: prevalence, risk factors and trigger events, Health and Social Care in the Community, 14 (4): 319-28.

Mayock, P., \& Sheridan, S. (2012). Women's journeys to homelessness: Key findings from a biographical study of homeless women in Ireland. Dublin: Trinity College.

Mayock, P., Sheridan, S. \& Parker, S. (2015).'It's just like we're going around in circles and going back to the same thing...'The dynamics of women's unresolved homelessness, Housing Studies DOI: 10.1080/02673037.2014.991378

McVicar, D., Moschion, J. and van Ours, J. (2015) From substance use to homelessness or vice versa? Social Science and Medicine, 136-137, 88-98.

Morrison, D. S. (2009). Homelessness as an independent risk factor for mortality: Results from a retrospective cohort study. International Journal of Epidemiology, 38: 877-883.

Muñoz, M., Crespo, M., \& Perez-Santos, E. (2005). Homelessness effects on men's and women's health. International Journal of Mental Health, 34(2): 47-61.

Netherlands Ministry of Health, Welfare and Sport (2006). Strategy Plan for Social Relief of 4 Major Cites. The Hague: Ministry of Health, Welfare and Sport. 
Nielsen, S. F., Hjorthøj, C. R., Erlangsen, A. \& Nordentoft, M. (2011). Psychiatric disorders and mortality among people in homeless shelters in Denmark: A nationwide register-based cohort study. Lancet, 377: 2205-2214.

O'Carroll, A., \& O'Reilly, F. (2008). Health of the homeless in Dublin: Has anything changed in the context of Ireland's economic boom? European Journal of Public Health, 18: 448-453.

Paquette, K. \& Bassuk, E. (2009). Parenting and Homelessness: Overview and Introduction to the Special Section. American Journal of Orthopsychiatry, 79: 292-298.

Pleace, N., Jones, A., \& England, J. (2000). Access to General Practice for People Sleeping Rough. York: Department of Health/University of York.

Pleace, N., \& Quilgars, D. (2004). Delivering Health Care to Homeless People: An effectiveness review. Edinburgh: Health Scotland.

Rayburn, N. R., Wenzel, S. L., Elliott, M. N., Hambarsoomians, K., Marshall, G. N., \& Tucker, J. S. (2005). Trauma, depression, coping, and mental health service seeking among impoverished women. Journal of Consulting and Clinical Psychology, 73: 667-677.

Razpotnik, Š . \& Dekleva, B. (2009a). Homelessness and the accessibility of the health care system. Socialna pedagogika, 13: 111-130.

Razpotnik, Š. \& Dekleva, B. (2009b). Brezdomstvo, zdravje in dostopnost zdravstvenih storitev (Homelessness, health and availability of health services). Ljubljana: Ministrstvo za zdravje.

Riley, E. D., Weiser, S. D., Sorensen, J. L., Dilworth, S., Cohen, J., \& Neilands, T. B. (2007). Housing patterns and correlates of homelessness differ by gender among individuals using San Francisco free food programs. Journal of Urban Health: Bulletin of the New York Academy of Medicine, 84: 415-422. 
Robertson, M. J., Clark, R. A., Charlebois, E. D., Tulsky, J., Long, H. L., Bangsberg, D. R., \& Moss, A. R. (2004). HIV seroprevalence among homeless and marginally housed adults in San Francisco. American Journal of Public Health, 94: 1207-1217.

Robertson M. J., \& Winkleby M. A. (1996). Mental health problems of homeless women and difference across subgroups. Annual Review of Public Health, 17: 311-336.

Scottish Executive (2005) Health and Homelessness Standards. Edinburgh: Scottish Executive.

Shakarishvili, A., Dubovskaya, L. K., Zohrabyan, L. S., St Lawrence, J. S., Aral, S. O., Dugasheva, L. G., LIBRA Project Investigation Team (2005). Sex work, drug use, HIV infection, and spread of sexually transmitted infections in Moscow, Russian Federation. The Lancet, 366: 57-60.

Smith, M., McGee. H. M., Shannon, W., \& Holohan, T. (2001). One hundred homeless women. Health status and health service use of homeless women and their children in Dublin. Dublin: Health Services Research Centre Department of Psychology \& Royal College of Surgeons in Ireland.

STA. Slovenska tiskovna agencija. Slovene press agency. (2012). It is 10 years since the beginning of ambulant for uninsured persons, 17.1.2012. Accessed 19.8.2013:

http://www.siol.net/novice/zdravje/2012/01/mineva_deset_let_od_zacetka_delovanja_ambula nte za_nezavarovane_osebe.aspx

Stein, J. A., Andersen, R. \& Gelberg, L. (2007). Applying the Gelberg-Andersen behavioural model for vulnerable populations to health services utilization in homeless women. Journal of Health Psychology, 12: 791-804.

Stewart, A. J., Steiman, M., Cauce, A. M., Cochran, B. N., Whitbeck, L. B., \& Hoyt, D. (2004). Victimization and posttraumatic stress disorder among homeless adolescents. Journal of the American Academy of Child Psychiatry, 43: 325-331 
Stoltenborgh, M., Van IJzendoorn, M. H., Euser, E. M., \& Bakermans-Kranenburg, M. J. (2011). A global perspective on child sexual abuse: Meta-analysis of prevalence around the world. Child Maltreatment, 16: 79-101.

Strehlau, V., Torchalla, I., Li, K., Schuetz, C., \& Kraus, M. (2012). Mental health, concurrent disorders, and health care utilization in homeless women. Journal of Psychiatric Practice, 18: 349-360.

Taylor, K. M., \& Sharpe, L. (2008). Trauma and post-traumatic stress disorder among homeless adults in Sydney. Australian and New Zealand Journal of Psychiatry, 42: 206-213.

Teruya, C., Longshore, D., Andersen, R. M., Arangua, L., Nyamathi, A., Leake, B., \& Gelberg, L. (2010). Health and health care disparities among homeless women. Women Health, 50: 719-736.

Tischler, V. A., \& Vostanis, P. (2007) Homeless Mothers: Is there a Relationship between Coping Strategies, Mental Health and Goal Achievement? Journal of Community \& Applied Social Psychology, 17: 85-102.

Torchalla, I., Strehlau, V., Li, K., \& Krausz, M. (2011). Substance use and predictors of substance dependence in homeless women. Drug and Alcohol Dependence, 118 (2-3): 173179.

Tucker, J. S., D'Amico, E. J., Wenzel, S. L, Golinelli, D., Elliott, M. N., \& Williamson, S. (2005). A prospective study of risk and protective factors for substance use among impoverished women living in temporary shelter settings in Los Angeles County. Drug and Alcohol Dependence, 80(1): 35-43.

Wenzel, S. L., Tucker, J. S., Elliott, M. N., Hambarsoomian, K., Perlman, J., Becker, K., Golinelli, D. (2004). Prevalence and co-occurrence of violence, substance use and disorder, and HIV risk behaviour: A comparison of sheltered vs. low-income housed women in Los Angeles County. Preventive Medicine, 39: 617-624. 
Wilson, M. (2005). Health-promoting behaviours of sheltered homeless women. Family \& Community Health: The Journal of Health Promotion \& Maintenance, 28 (1): 51-63.

World Health Organization (WHO) (2013). World health report 2013: Research for universal health coverage. Geneva: WHO.

Wright, N. M. J., \& Tompkins, C. N. E. (2006). How can health services effectively meet the health needs of homeless people? British Journal of General Practice, 56: 286-293.

Zugazaga, C. (2004). Stressful life event experiences of homeless adults: A comparison of single men, single women, and women with children. Journal of Community Psychology, 32: 643-654. 